\title{
A green chemical approach for synthesis of shape anisotropic gold nanoparticles
}

\author{
S. S. Kalyan Kamal · J. Vimala $\cdot$ P. K. Sahoo • \\ P. Ghosal $\cdot$ S. Ram $\cdot$ L. Durai
}

Received: 23 December 2013/ Accepted: 20 May 2014/Published online: 6 June 2014

(C) The Author(s) 2014. This article is published with open access at Springerlink.com

\begin{abstract}
A complete green chemical reaction between aurochloric acid and tea polyphenols resulted in the reduction of $\mathrm{Au}^{3+} \rightarrow \mathrm{Au}^{0}$. The reaction was carried out in a Teflon-coated bomb digestion vessel at $200{ }^{\circ} \mathrm{C}$. It was observed that with increasing the reaction time from 1 to $5 \mathrm{~h}$, the shape of the nanoparticles changed from sphericalto rod-like structures. The reaction was followed with the help of UV-vis spectrometer, which showed a single absorption peak at $548 \mathrm{~nm}$ for 1-h reaction product and two peaks for a 5-h reaction product at 533 and $745 \mathrm{~nm}$ corresponding to the transverse and longitudinal surface plasmon resonance bands. Microstructures obtained from transmission electron microscope revealed that the samples obtained after 1-h reaction are predominantly spherical in shape with an average size of $15 \mathrm{~nm}$. Whereas samples obtained after $5 \mathrm{~h}$ of reaction exhibited rod-like structures with an average size of $45 \mathrm{~nm}$.
\end{abstract}

Keywords Gold nanorods - Green chemical synthesis . Tea polyphenols $\cdot$ UV-vis spectroscopy

\section{Introduction}

Synthesis of gold nanoparticles (Au NPs) has drawn the attention of researchers because of their extensive

S. S. Kalyan Kamal $(\bowtie) \cdot$ J. Vimala · P. K. Sahoo · P. Ghosal ·

L. Durai

Defence Metallurgical Research Laboratory, Kanchanbagh,

Hyderabad 500 058, India

e-mail: kalyanchem03@rediffmail.com

S. Ram

Materials Science Centre, Indian Institute of Technology,

Kharagpur 721 302, India applications in the development of new technologies in areas such as chemistry, catalysis, electronics, medicine and biotechnology [1-3]. As both size and shape of Au NPs affect optical and electronic properties, a number of methods have been reported for the preparation of Au NPs with varying sizes and shapes [4-6]. The surface electrons of Au NPs exhibit a phenomenal behavior of collective oscillation and absorption of light, which is known as surface plasmon resonance (SPR). The remarkable shapedependent optical property of gold nanorods and spheres is a typical example, wherein gold nanorods exhibit two absorption peaks arising from the transverse and longitudinal surface plasmon resonances (SPRs), whereas the spherical particles display only a single SPR peak $[4,5]$. Au NPs can be synthesized by conventional chemical and physical methods [7-9]. Many of the synthetic routes for development of nanomaterials use toxic reagents that make them unsuitable for biological use and also have adverse effect on the environment. Furthermore, these methods are expensive as they require high energy, long time and sophisticated equipments to carry out the reactions. These concerns over several chemical and physical synthetic techniques have resulted in attempts to develop biological approaches. Therefore, development of green processes for the synthesis of NPs has evolved into an important branch of nanotechnology. Green nanotechnology uses biomolecules present either in plant extracts or microorganism as novel reducing and capping agents. They not only suffice as environmentally friendly routes but also as economically sustainable alternatives to chemical and physical methods.

Recently, many biosynthetic routes have been reported for synthesis of Au NPs through micro-organisms such as algae, fungi and bacteria. However, due to their cumbersome procedures such as maintaining cell cultures under specified laboratory conditions have made them less 
attractive, when compared to using plant products for synthesis of nanomaterials. Many plants or plant products have been employed for the synthesis of Au NPs, some of which include, Emblica officinalis, Acacia nilotica (Babool), alfalfa biomass, geranium, Azadirachta indica leaves, gum kondagogu, gram-beans and tea leaves [1017]. Camellia sinensis commonly known as tea is a rich source of polyphenolic compounds, which exhibits a variety of health benefits such as protection against heart diseases, cancer and the paralytic actions of botulinum neurotoxins [18, 19]. These attractive health benefits apart from its complete green approach have turned tea extract as an important species for synthesis of NPs. However, tea extract has been utilized only for the synthesis of spherical NPs with SPR bands in the visible region. To enhance its biocompatibility, the SPR band needs to be tuned in such a way that it lies close to the NIR region, where biological tissues tend to absorb minimally. Therefore, synthesis of $\mathrm{Au}$ NPs with rod-like structures using green processes becomes crucial. Many reports have earlier been published to control the shape of Au NPs to form nanorods, but they require multi-pronged and cumbersome experimental procedures such as seed-mediated growth [20-22]. In this work, we report a novel, simple, single-stage selective biosynthesis route for production of Au NPs in the form of spheroids and rods. To obtain the desired shape of Au NPs, aqueous chloroaurate ions were reacted with an extract of Camellia sinensis (tea) leaves in a stainless steel bomb digestion vessel for different time intervals.

\section{Methods}

Hydrogen tetrachloroaurate $\left(\mathrm{HAuCl}_{4} \cdot 3 \mathrm{H}_{2} \mathrm{O}, 99.9 \%\right.$ pure $)$ was obtained from Aldrich chemicals, Germany. Commercially available tea powder from Tata tea Limited, India, was used for preparing the tea aliquot. Ultra high pure water with a resistivity of $18.2 \mathrm{M} \Omega-\mathrm{cm}$ was used as reaction medium for the synthesis Au NPs. $2.0 \mathrm{~g}$ of tea leaves was weighed and transferred into a 100-ml volumetric flask and made up to the mark with water. The contents of the flask were dispersed by agitating it in a shaking water bath for $30 \mathrm{~min}$ and then left over night to collect the released Camellia sinensis leaf extract. The reddish brown color extract was decanted after centrifuging at $200 \mathrm{rpm}$ for $30 \mathrm{~min}$ to separate any un-dissolved ingredients. A dilute solution of gold $(0.05 \mathrm{M})$ was prepared by dissolving suitable amount of $\mathrm{HAuCl}_{4} \cdot 3 \mathrm{H}_{2} \mathrm{O}$ in water. To carry out the $\mathrm{Au}^{3+} \rightarrow \mathrm{Au}$ reaction, $8 \mathrm{ml}$ of tea extract and $2 \mathrm{ml}$ of $0.05 \mathrm{M} \mathrm{HAuCl}_{4} \cdot 3 \mathrm{H}_{2} \mathrm{O}$ solution were pipetted out into a Teflon-coated stainless steel bomb digestion vessel and the container was sealed tightly. The bomb digestion vessel along with its reactants was then placed in an oven at $200{ }^{\circ} \mathrm{C}$ for different time periods of 1 and $5 \mathrm{~h}$ as shown in Table 1. A PG instrument (model T90+), UV-vis spectrometer was used to analyze samples collected from different reactions. To study the effective capping of biomolecules on the Au NPs surface, a Tensor 27 Fourier transform infrared spectrometer (FTIR) was used. Crystal structure of as-synthesized Au NPs was obtained using a Philips PW3020 X-ray diffractometer (XRD) consisting of an X-ray source of $\mathrm{CuK} \alpha$ with $0.15405 \mathrm{~nm}$ wavelength. A transmission electron microscope (TEM) of FEI TECHNAI G2 was used for both imaging the $\mathrm{Au}$ NPs and obtaining their selected area electron diffraction (SAED) patterns. For TEM imaging, a small drop of the sample solution was dispersed onto a specific 3-mm carbon-coated copper grid and was dried in a desiccator at room temperature before TEM imagining.

\section{Results and discussion}

The chemical reduction of aqueous $\mathrm{HAuCl}_{4}$ solution under different experimental conditions was followed visually. The reactant solution from experiment 1 remained yellow even after $1 \mathrm{~h}$ of reaction in the bomb vessel, which indicates that the $\mathrm{Au}^{3+}$ ions did not get reduced. A similar reaction carried out in experiment 2 with $8 \mathrm{ml}$ of tea leaf extract changed its color from yellow to pale pink indicating the reduction of $\mathrm{Au}^{3+}$ ions to $\mathrm{Au}$. These results indicate that aurochloric acid does not reduce hydrothermally in the bomb digestion vessel under the given conditions in experiment 1. It also proves that the tea polyphenols are very essential for the reduction of $\mathrm{Au}^{3+}$ ions to $\mathrm{Au}$ NPs. Tea consists of two major categories of polyphenolic compounds, namely thearubigins and theaflavins. The three major constituents of theaflavins are Epigallocatechin gallate, Epigallocatechin and Epicatechin gallate [17]. Figure 1a-c depicts the chemical structures of
Table 1 Experimental conditions for synthesis of $\mathrm{Au}$ NPs of selective shapes upon reaction of Camellia sinensis with $0.05 \mathrm{M} \mathrm{Au}^{3+}$ species in a bomb digestion vessel at $200{ }^{\circ} \mathrm{C}$

\begin{tabular}{llllll}
\hline Experiment & $\begin{array}{l}\mathrm{HAuCl}_{4} \cdot 3 \mathrm{H}_{2} \mathrm{O} \\
(\mathrm{mL})\end{array}$ & $\begin{array}{l}\text { Camellia sinensis } \\
\text { extract }(\mathrm{mL})\end{array}$ & $\begin{array}{l}\text { Time } \\
(\mathrm{h})\end{array}$ & $\begin{array}{l}\text { Particle } \\
\text { size }(\mathrm{nm})\end{array}$ & Shape \\
\hline 1 & 2 & 0 & 1 & - & - \\
2 & 2 & 8 & 1 & 15 & Spherical \\
3 & 2 & 8 & 5 & 45 & Rods \\
\hline
\end{tabular}


Fig. 1 Chemical structures along with their 3D models of the three major theaflavin compounds a Epigallocatechin gallate, b Epigallocatechin, c Epicatechin gallate and d a typical Thearubigin<smiles>O=C(O[C@H]1Cc2c(O)cc(O)cc2O[C@H]1c1cc(O)c(O)c(O)c1)c1cc(O)c(O)c(O)c1</smiles>

(a)

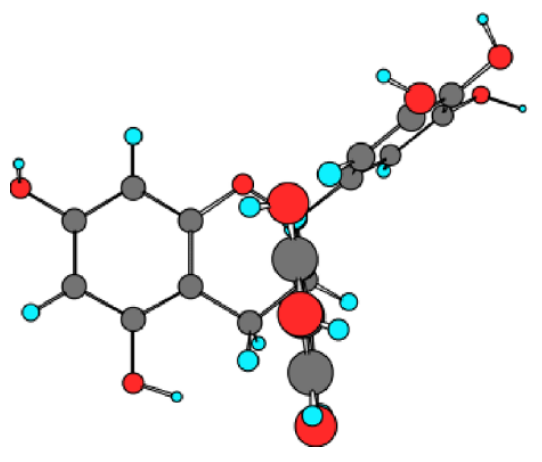<smiles>Oc1cc(O)c2c(c1)O[C@H](c1cc(O)c(O)c(O)c1)[C@H](O)C2</smiles>

(b)

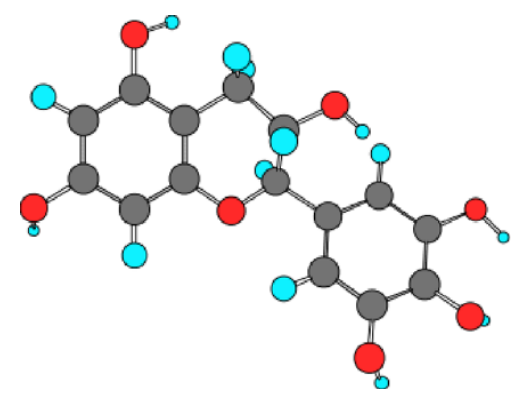

(c)

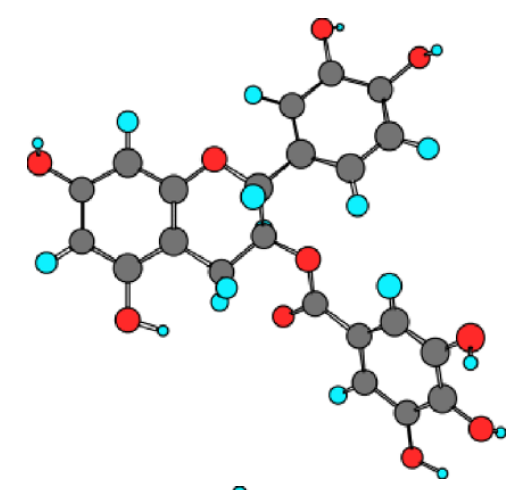<smiles>O=C(O)CC(c1cc([C@@H]2Oc3cc(O)cc(O)c3C[C@H]2P)cc(O)c(=O)c1C(=O)O)[C@H]1Oc2cc(O)cc(O)c2CC1P</smiles>

(d)

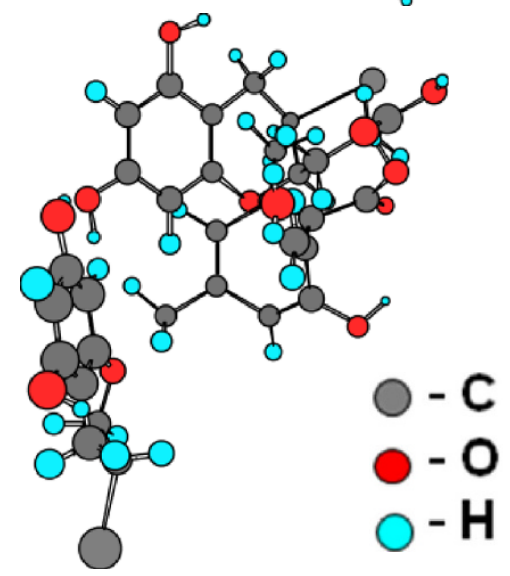

the three major theaflavin compounds and from their structures it could be observed that all the chemical compounds consist of hydroxyl $(\mathrm{OH})$ groups adjacent to each other. This arrangement is similar to 1,2 diols, which is essential for the polyphenols to act as reducing agents. Therefore, as shown in Table 1, these polyphenolic compounds act as novel reducing agents for the synthesis of $\mathrm{Au}$ NPs in the above reactions. Whereas the structure shown in 


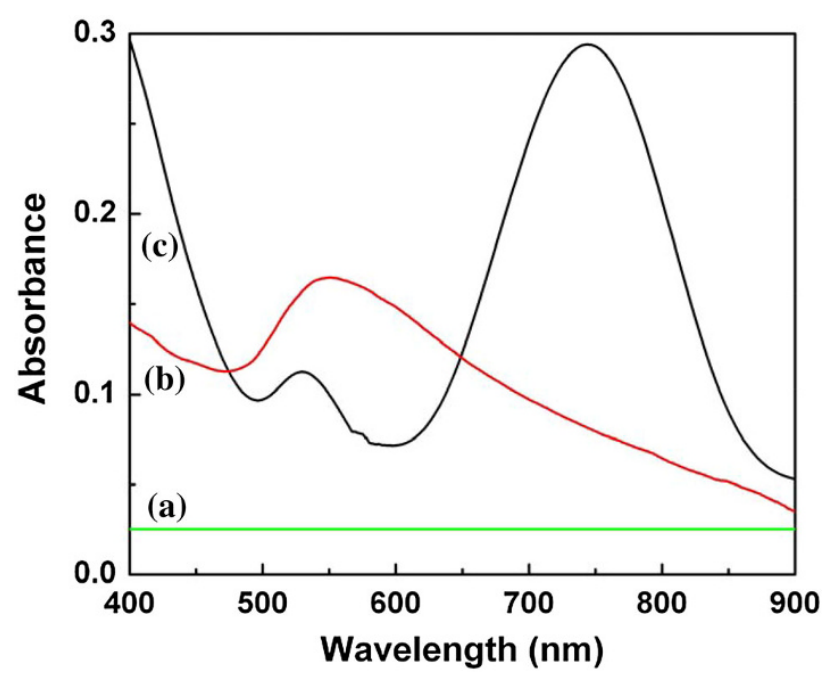

Fig. 2 UV-vis absorption spectra obtained from aqueous $\mathrm{HAuCl}_{4}$ solution upon reaction in a bomb digestion vessel at $200{ }^{\circ} \mathrm{C}$ under different reaction conditions a without tea extract for $1 \mathrm{~h}, \mathbf{b}$ with tea extract for $1 \mathrm{~h}$ and $\mathbf{c}$ with tea extract for $5 \mathrm{~h}$

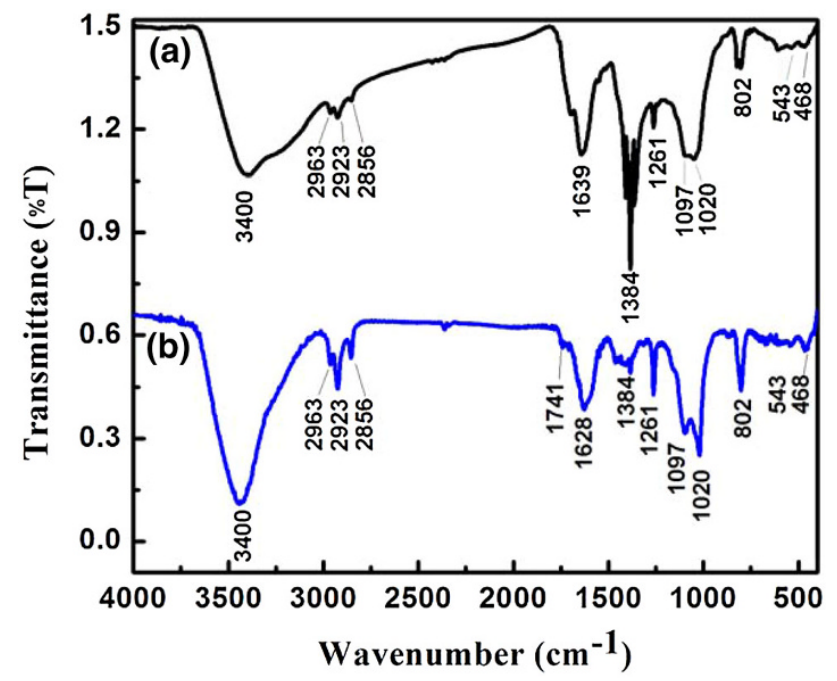

Fig. 3 FTIR spectra of a un-reacted tea extract and b colloidal solution of Au NPs obtained after a 5-h reaction

Fig. 1d is that of a typical thearubigin possessing the carboxylic acid $(\mathrm{COOH})$ functional group, well known for their capping abilities $[18,23]$. Therefore, the tea extract performs the dual role of novel reducing agent as well as an efficient bio-surfactant.

The reaction products were further characterized by UV-visible spectroscopy. Figure $2 \mathrm{a}-\mathrm{c}$ shows three typical $\mathrm{UV}$-vis spectra obtained from aqueous $\mathrm{HAuCl}_{4}$ solution upon reaction in a bomb digestion vessel at $200{ }^{\circ} \mathrm{C}$ under different reaction conditions. Figure 2a shows the spectrum recorded for the solution from experiment 1 . It could be observed that only a flat line exists in the range of

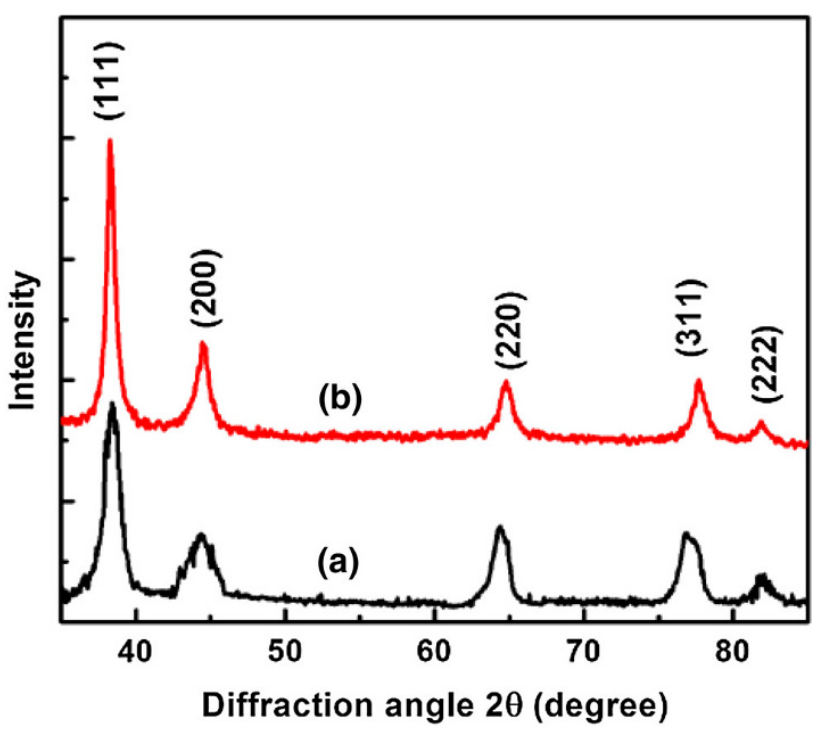

Fig. 4 X-ray diffraction patterns obtained from Au NPs a experiment 2 and $\mathbf{b}$ experiment 3

$400-900 \mathrm{~nm}$ and the absence of any peaks in this region indicates that there is no change in the metal oxidation state of $\mathrm{Au}^{3+}$ ions. Figure $2 \mathrm{~b}$ shows the UV-vis spectra recorded for the sample solution from experiment 2. Upon reaction for $1 \mathrm{~h}$ with $8 \mathrm{ml}$ of black tea extract, the appearance of a single absorption peak centered at about $548 \mathrm{~nm}$ was observed. This could be attributed to the transverse SPR band of Au NPs, which indicates that upon reaction with the tea polyphenols, through the reduction of $\mathrm{Au}^{3+}$ ions, metallization of Au occurs. A single broad peak also leads to an inference that the Au NPs are isotropic in shape and uniform in size. As the reaction time was increased from 1 to $5 \mathrm{~h}$, a drastic change in the UV-vis spectra was observed as shown in Fig. 2c. The peak at $548 \mathrm{~nm}$ diminished in its intensity and slightly blue shifted to $533 \mathrm{~nm}$. A new broad peak with $\lambda_{\max }$ at $745 \mathrm{~nm}$ was observed, which could be attributed to a typical signal arising from the longitudinal SPR of Au nanorods. The above result indicates that upon extended heating, the spherical Au NPs convert into rod-like structures. However, a small peak persisting at $533 \mathrm{~nm}$ indicates that a minor fraction $<10 \%$ of the particles still remains in the form of nanospheres. The presence of typical SPR bands in the UV-vis region for Au samples indicates that the particles are in the nanometric range. This also proves that the polyphenolic constituents of tea not only act as good reducing agents, but also perform the function of stabilization of Au NPs by capping on to their surfaces.

Figure 3 shows the FTIR spectra of (a) un-reacted tea extract and (b) colloidal solution of Au NPs obtained after a 5-h reaction. To understand the nature of interaction between the tea extract and $\mathrm{Au}^{3+}$ ions, FTIR spectra were 
analyzed in detail. From Fig. 3a, it could be observed that the un-reacted tea extract consists of a broad peak in the region of $3,200-3,500 \mathrm{~cm}^{-1}$ corresponding to the $\mathrm{O}-\mathrm{H}$ stretch and the peaks at 2,963,2,923 and 2,854 $\mathrm{cm}^{-1}$ could be attributed to the $\mathrm{sp}^{3}$ and $\mathrm{sp}^{2} \mathrm{C}-\mathrm{H}$ stretching vibrations of the organic moieties. Peak at $1,639 \mathrm{~cm}^{-1}$ could be attributed to the $\mathrm{C}=\mathrm{O}$ stretch of the acid groups present in thearubigins and the peak at $1,384 \mathrm{~cm}^{-1}$ could be assigned to the stretching vibration of carboxylate ion (-COO-). A peak at $1,261 \mathrm{~cm}^{-1}$ shows the $-\mathrm{OH}$ deformation vibrations in the polyphenolic compounds and peaks at 1,097 and $1,020 \mathrm{~cm}^{-1}$ could be attributed to the $\mathrm{C}-\mathrm{O}$ and $\mathrm{C}-\mathrm{OH}$ single-bond vibrations. The peaks present at 802,543 and $468 \mathrm{~cm}^{-1}$ confirm the presence of aromatic-substituted rings. Except for a new peak at $1,741 \mathrm{~cm}^{-1}$ and a slight shift in the $\mathrm{C}=\mathrm{O}$ stretch from 1,639 to $1,628 \mathrm{~cm}^{-1}$, rest of the peaks remain unchanged in the spectrum obtained from that of Au NPs after the reaction with tea extract as shown in Fig. 3b. The new peak at $1,741 \mathrm{~cm}^{-1}$ could possibly be due to the conversion of $\mathrm{C}-\mathrm{OH}$ group to $\mathrm{C}=\mathrm{O}$ group during the reduction reaction of $\mathrm{Au}^{3+} \rightarrow$ Au. The very low intensity of this peak also suggests that most of the $\mathrm{C}-\mathrm{OH}$ groups remain as such and only a small fraction of the them converts to $\mathrm{C}=\mathrm{O}$ group, which is in good agreement with the fact that tea aliquot is taken in large excess to carry out the reaction. A red shift in the carbonyl frequency by $11 \mathrm{~cm}^{-1}$ indicates a weak coordination between the carbonyl group and the surface of Au NPs, which proves that
Fig. 5 TEM micrographs of $\mathrm{Au}$ nanoparticles obtained after reaction in a bomb digestion vessel at $200{ }^{\circ} \mathrm{C}$ under different reaction conditions a with tea extract for $1 \mathrm{~h}$ and $\mathbf{b}$ with tea extract for $5 \mathrm{~h}$. Respective selected area electron diffraction patterns are shown on the right. c Energy dispersive $\mathrm{X}$-ray spectra obtained from $5 \mathrm{~h}$ reaction product
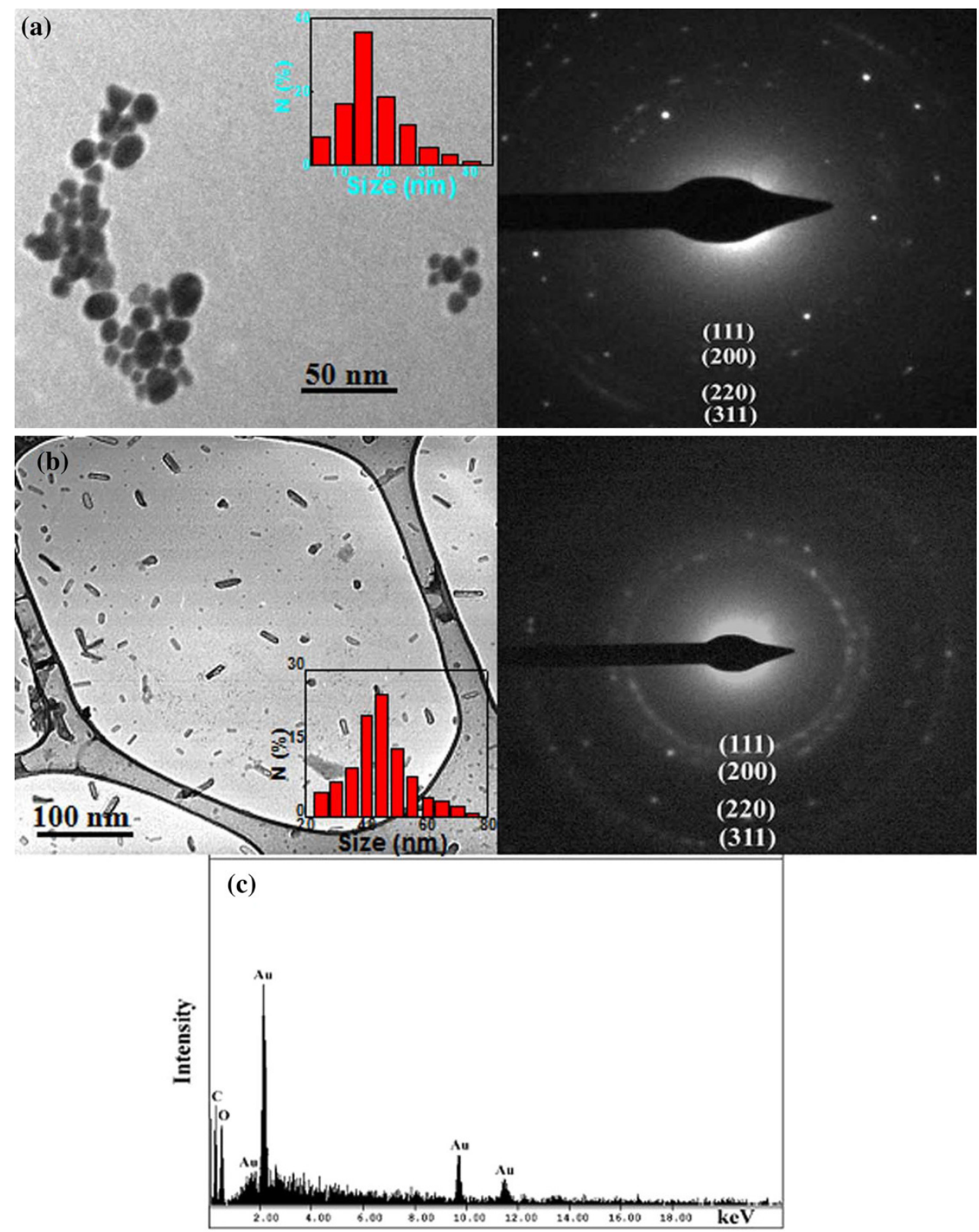
the Au NPs are protected by the polyphenolic compounds present in tea.

Figure 4 shows typical XRD patterns from recovered $\mathrm{Au}$ NPs (a) experiment 2 and (b) experiment 3 . They consist of five characteristic peaks at $2 \theta$ values of $38.27^{\circ}, 44.49^{\circ}$, $64.69^{\circ}, 77.73^{\circ}$ and $81.91^{\circ}$, which can be discerned to (111), (200), (220), (311), and (222) lattice reflections of a facecentered cubic (fcc) structure of Au (JCPDS JCPDS 01-1172), respectively. From the XRD patterns, the lattice parameter (a) was calculated for both (a) and (b) samples as 0.4076 and $0.4069 \mathrm{~nm}$, respectively. Compared to peaks obtained from sample (b), Fig. 4a shows slightly broader peaks. Average crystallite size was calculated from the peak broadening using the Debye-Scherrer relation, which presents a value of $12 \mathrm{~nm}$ for sample (a) and $18 \mathrm{~nm}$ for sample (b).

Figure 5a shows representative TEM images recorded from the drop-coated sample of the Au NPs, synthesized by treating the aurochloric acid solution with an extract of black tea after $1 \mathrm{~h}$ in a bomb digestion vessel at $200{ }^{\circ} \mathrm{C}$ (experiment 2). As shown in the inset, TEM images obtained from the above sample exhibit predominantly spherical particles of $15 \mathrm{~nm}$ size with narrow size distribution. However, few triangles and rods were also observed in the same sample. Selected area electron diffraction (SAED) pattern obtained from the above sample is shown on the right. The SAED pattern consists of four concentric rings, which could be assigned to (111), (200), (220) and (311) planes of fcc structure, which is in good agreement with the XRD pattern observed in Fig. 4a. Figure 5b shows TEM images for samples obtained from experiment 3 . The micrograph depicts predominantly (>90\%) rod-like structures with an average size of $45 \mathrm{~nm}$. This result corroborates well with the UV-vis spectrum observed in Fig. 2c, where two peaks were found with the major one at $548 \mathrm{~nm}$ and the minor peak at $533 \mathrm{~nm}$, indicating that the major portion of the Au NPs exists in the form of nanorods and only $<10 \%$ of them retains their spherical shape. This is evident from the inset in Fig. 5b, which shows the size distribution graph depicting a small fraction of $\mathrm{Au}$ NPs in the range of 20-25 nm size. The SAED pattern obtained from the rods is shown on the right, which also exhibits a typical fcc structure of Au. Figure 5c shows the energy dispersive X-ray (EDX) spectra obtained from the gold nanorods, which confirm the presence of gold as major constituent and carbon and oxygen as trace impurities. The traces of carbon and oxygen could be attributed to the polyphenolic coating over the Au NPs.

The above results prove that Au NP formation occurs as early as $1 \mathrm{~h}$ after reaction in the bomb digestion vessel, whereas a typical reaction takes $4-5 \mathrm{~h}$ to complete in an open vessel [16]. This shows that the rate of reaction between $\mathrm{Au}^{3+}$ ions and polyphenols increases rapidly when heated in a closed container. The 5-h reaction product, however, shows a distinct microstructure comprising predominantly of nanorods throughout the grid. The phenomenal change in microstructure from experiment 2-3 could be attributed to the fact that a lot of pressure develops inside the bomb upon constant heating at $200{ }^{\circ} \mathrm{C}$ for $5 \mathrm{~h}$. This excess pressure leads to the conversion of spherical Au NPs into rodlike structures. Similar results were also observed in the case of cobalt NPs prepared by a chemical reaction in bomb digestion vessel [24].

\section{Conclusions}

We have successfully demonstrated a complete green chemical route for the synthesis of Au NPs with different shapes (spheres and rods). Shape anisotropy of Au NPs could be achieved by simply carrying out the reaction in a bomb digestion vessel for different reaction times. Spherical Au NPs from experiment 2 were of $15 \mathrm{~nm}$ in size and exhibited a single SPR band at $548 \mathrm{~nm}$, whereas the $\mathrm{Au}$ nanorods from experiment 3 were of $45 \mathrm{~nm}$ in size and contained two SPR bands in the UV-vis region. The longitudinal SPR band of gold nanorods at $745 \mathrm{~nm}$ is of great importance for biological applications. An added advantage of synthesizing Au nanorods here is that the NPs are capped with biomolecules (tea polyphenols) which not only are bio-compatible but also exhibit other health benefits.

Acknowledgments This work was supported by the Defense Research and Development Organization (DRDO), Ministry of Defense, Government of India. We extend our thanks to the Director, DMRL, Hyderabad, for his keen interest in this work and also permitting us to publish these results. The authors are also thankful to Dr. M. Vijayakumar for his support, while carrying out this work.

Conflict of interest Authors declare no competing financial interests. The authors have no other relevant affiliations or financial involvement with any organization or entity with a financial interest in or financial conflict with the subject matter of materials discussed in the manuscript apart from those disclosed. No writing assistance was utilized in the production of this manuscript.

Authors' contributions SSKK, JV and PKS hypothesized and executed the experiments, collected and interpreted the data, and wrote the manuscript. PG assisted in collecting, analyzing and interpreting the TEM micrographs. SR and LD were involved in writing and editing the manuscript and interpreting the results. All authors have read and approved the final manuscript.

Open Access This article is distributed under the terms of the Creative Commons Attribution License which permits any use, 
distribution, and reproduction in any medium, provided the original author(s) and the source are credited.

\section{References}

1. Aromal, S.A., Babu, K.V.D., Philip, D.: Characterization and catalytic activity of gold nanoparticles synthesized using ayurvedic arishtams. Spectrochim. Acta A Mol. Biomol. Sepctrosc. 96, 1025-1030 (2012)

2. Spadavecchia, J., Casale, S., Boujday, S., Pradier, C.-M.: Bioconjugated gold nanorods to enhance the sensitivity of FT-SPRbased biosensors. Colloids Surf. B Biointerf. 100, 1-8 (2012)

3. Yigit, M.V., Medarova, Z.: In vivo and ex vivo applications of gold nanoparticles for biomedical SERS imaging. Am. J. Nuc. Med. Mol. Imaging 2, 232-241 (2012)

4. Aizpurua, J., Hanarp, P., Sutherland, D.S., Kall, M., Bryant, G.W., Abajo, F.J.G.: Optical properties of gold nanorings. Phy. Rev. Lett. 90, 057401 (2003)

5. Gao, J., Bender, C.M., Murphy, C.J.: Dependence of the gold nanorod aspect ratio on the nature of the directing surfactant in aqueous solution. Langmuir 19, 9065-9070 (2003)

6. Vijay, C.V., Swecha, A., Christian, U., Santosh, K.S.: Biogenic gold nanotriangles from Saccharomonospora sp., an endophytic actinomycetes of Azadirachta indica A. Juss. Int. Nano Lett. 3, 21-28 (2013)

7. Esumi, K., Kameo, A., Suzuki, A., Torigoe, K., Yoshimura, T., Koide, Y., Shosenji, H.: Preparation of gold nanoparticles using 2-vinylpyridine telomeres possessing multi-hydrocarbon chains as stabilizer. Coll. Surf. A 176, 233-239 (2003)

8. Han, M.Y., Quek, C.H., Huang, W., Chew, C.H., Gan, L.M.: A simple and effective chemical route for the preparation of uniform nonaqueous gold colloids. Chem. Mater. 11, 1144-1147 (1999)

9. Chen, Z.Y., Zhou, Y., Wang, C.Y., Zhu, Y.R.: A novel ultraviolet irradiation technique for shape-controlled synthesis of gold nanoparticles at room temperature. Chem. Mater. 11, 2310-2312 (1999)

10. Balaprasad, A., Chinmay, D., Ahmad, A., Sastry, M.: Biosynthesis of gold and silver nanoparticles using Emblica Officinalis fruit extract, their phase transfer and transmetallation in an organic solution. J. Nanosci. Nanotechnol. 5, 1665-1671 (2005)

11. Gardea-Torresdey, J.L., Parsons, J.G., Gomez, E., Peralta-Videa, J., Troiani, H.E., Santiago, P., Yacaman, M.J.: Formation and growth of Au nanoparticles inside live Alfalfa plants. Nano Lett. 2, 397-401 (2002)

12. Shankar, S.S., Ahmad, A., Pasricha, R., Sastry, M.: Bioreduction of chloroaurate ions by geranium leaves and its endophytic fungus yields gold nanoparticles of different shapes. J. Mater. Chem. 13, 1822-1826 (2003)

13. Rakhi, M., Braja, G.B., Nabasmita, M.: Acacia nilotica (Babool) leaf extract mediated size-controlled rapid synthesis of gold nanoparticles and study of its catalytic activity. Int. Nano Lett. 3, 53-58 (2013)

14. Vinod, V.T.P., Saravanan, P., Sreedhar, B., Devi, D.K., Sashidhar, R.B.: A facile synthesis and characterization of Ag, Au and Pt nanoparticles using a natural hydrocolloid gum kondagogu (Cochlospermum gossypium). Colloids Surf. B Biointerf. 83, 291-298 (2011)

15. Kalyani, G., Vithal, A., Liu, J.-Y., Ling, Y.-C.: Microscale size triangular gold prisms synthesized using Bengal gram beans (Cicer Arietinum) extract and $\mathrm{HAuCl}_{4} \cdot 3 \mathrm{H}_{2} \mathrm{O}$ : a green biogenic approach. J. Nanosci. Nanotechnol. 6, 3746-3751 (2006)

16. Kamal, S.S.K., Sahoo, P.K., Premkumar, M., Sreedhar, B., Ram, S.: A facile green-chemical-synthetic-route for producing gold nanoparticles using Camellia sinensis. Adv. Sci. Lett. 3, 144-148 (2010)
17. Nune, S.K., Chanda, N., Shukla, R., Katti, K., Kulkarni, R.R., Thilakavathy, S., Mekapothula, S., Kannan, R., Katti, K.V.: Green nanotechnology from tea: phytochemicals in tea as building blocks for production of biocompatible gold nanoparticles. J. Mater. Chem. 19, 2912-2920 (2009)

18. Yang, C.S., Wang, X., Lu, G., Picinich, S.C.: Cancer prevention by tea: animal studies, molecular mechanisms and human relevance. Nat. Rev. Cancer 9, 429-439 (2009)

19. Satoh, E., Ishii, T., Shimizu, Y., Sawamura, S.-I., Nishimura, M.: Black tea extract, thearubigin fraction, counteract the effects of botulinum neurotoxins in mice. Br. J. Pharmacol. 132, 797-798 (2001)

20. Jana, N.R., Gearheart, L., Murphy, C.J.: Wet chemical synthesis of high aspect ratio cylindrical gold nanorods. J. Phys. Chem. B. 105, 4065-4067 (2001)

21. Altansukh, B., Yao, J., Wang, D.: Synthesis and characterization of gold nanorods by a seeding growth method. J. Nanosci. Nanotechnol. 8, 1-4 (2008)

22. Kozek, K.A., Kozek, K.M., Wu, W.-C., Mishra, S.R., Tracy, J.B.: Large scale synthesis of gold nanorods through continuous secondary growth. Chem. Mater. 25, 4537-4544 (2013)

23. Kamal, S.S.K., Sahoo, P.K., Premkumar, M., Vimala, J., Ram, S., Durai, L.: A novel green chemical route for synthesis of silver nanoparticles using Camellia sinensis. Acta Chim. Slov. 57, 808-812 (2010)

24. Kamal, S.S.K., Sahoo, P.K., Vimala, J., Raja, M.M., Durai, L., Ram, S.: Facile synthetic route for synthesis of cobalt nanorods and dendritic structures using a bomb digestion vessel. J. Exp. Nanosci. 8, 621-628 (2013)

S. S. Kalyan Kamal received his $\mathrm{Ph}$. D. in materials science from Indian Institute of Technology, Kharagpur and is currently serving as a Scientist in Defense Metallurgical Research Laboratory, Hyderabad, India. His research interests are in the area of magnetic nanomaterials and green chemical synthesis of nanoparticles.

J. Vimala is currently working as a Technical Officer in Defense Metallurgical Research Laboratory, Hyderabad, India. Her research interests are in the area of chemical characterization of materials and green chemical synthesis of nanoparticles.

P. K. Sahoo is currently serving as a Scientist in Defense Metallurgical Research Laboratory, Hyderabad, India. His research interests include synthesis of refractory-based nanomaterials and nanocomposites.

P. Ghosal is as a senior Scientist and head of electron microscopy group in Defense Metallurgical Research Laboratory, Hyderabad, India. His specialization is in the field of microstructural characterization of nanomaterials.

S. Ram is currently the Head and Professor at Materials Science Centre, Indian Institute of Technology, Kharagpur, West Bengal, India. His research interests include nanotechnology, magnetic materials and green chemistry.

L. Durai is a senior Scientist currently serving as a group head, analytical chemistry group, Defense Metallurgical Research Laboratory, Hyderabad, India. His research interests include chemical characterization of materials and single crystal growth. 